\title{
Descer até ao fundo, onde está o escuro
}

\author{
Hélder Wasterlain
}

Titulo: Câmara. Direcção artística: André Maranha, Gonçalo Ferreira de Almeida, Helena Tavares, João Rodrigues, Maria Duarte. Co-produção: Teatro Municipal Maria Matos e Projecto Teatral. Local e data de estreia:Teatro Municipal Maria Matos, Lisboa, 9 de Fevereiro de 2010.

Para descrever a experiência que o espectáculo Câmara proporciona a cada um dos espectadores é necessário utilizar um discurso do tipo "câmara" ao ombro. Neste caso, ao meu ombro. Câmara é um espectáculo pessoal. Pessoal porque depois de receber um esquema (ver imagem em anexo) das mãos do responsável pela frente de sala e de ouvir umas genéricas indicações - "pode levar o tempo que quiser" e "consulte o esquema em caso de dúvida" entro sozinho na sala de espectáculos do Teatro Municipa Maria Matos. Atrás de mim, o som da porta a fechar-se. À minha frente, a escuridão, a solidão e o silêncio. Abro e fecho os olhos três vezes, para me adaptar ao novo. Lentamente a escuridão vai ficando menos escuridão. Sem sair do sítio onde fiquei depositado, reparo que existem três pontos iluminados por uma fraca luz: o corredor lateral da plateia, as escadas de acesso da plateia para o palco e o palco. Avanço cauteloso e sigo a luz. Percorro o corredor, subo as escadas de acesso e paro no palco. Olho para a plateia. Ninguém. Por instantes o calafrio de poder estar a ser, eu próprio, o actor do espectáculo. No palco uma rampa descendente e preta, com uma luz a definir os seus contornos. Consulto o esquema (ver imagem em anexo). A rampa levar-me-á ao sub-palco, depois, já lá em baixo, tenho uma câmara anecóica, uma pilha, uma câmara de eco, uma fresta e um microfone ligado a uma caixa negra. Desço a rampa sem ainda entender o que vou encontrar. É bastante inclinada. À medida que desço penetro numa nova escuridão, mais densa que a primeira. Chego ao fim da rampa e não encontro senão silêncio e escuridão. Os olhos habituam-se ao novo com apenas três piscares. Ao centro da câmara uma pilha de tijolo burro,

Hélder Wasterlain é aluno do $2 .^{\circ}$ Ano de Teatro - Ramo Dramaturgia na Escola Superior de Teatro e disposta de forma organizada. Na verdade, só consigo descodificar estes elementos porque há um fio de luz irregular que atravessa uma fresta iluminando parte dos tijolos. Esta é aqui a única fonte de luz. Entro na câmara anecóica tacteando os seus limites. Pouco a pouco, o corpo e os sentidos vão adquirindo confiança para avançar,

sempre em busca da mínima luz. Em cima da pilha de tijolos está um microfone. Continuo a tactear o espaço lentamente. Contorno com cuidado a pilha para ver qual é a origem daquela luz irregular. Aproximo-me da fresta e espreito para o interior. Vejo uma projecção vídeo em sequência repetida, cujas imagens mostram uma paisagem em deslocação, como se estivéssemos num comboio. A paisagem passa e são as suas sombras que iluminam os tijolos. Sento-me neles. Se calhar não devia, mas a vontade de sentir todos os elementos que faziam parte desta câmara insonorizada foi maior. E fico - não foi isso o que o responsável pela frente de sala me disse? Olho para as imagens, sempre em sequência repetida, sinto os tijolos, oiço o vácuo, pressinto que alguém me ouvirá, nem que seja dali a cem anos, e apetece-me ficar ali como um arqueólogo a escavar razões, significados e sentidos na câmara onde o tempo parou. E fico.

Depois da submersão há que emergir e fazer o percurso de regresso. Subo a rampa, não sem antes olhar pela última vez para o espaço que abandono, com uma sensação de irrepetivel. Sinto a luz a aumentar à medida que me aproximo do palco. Agora a luz fere os olhos. Ninguém na plateia. Olho para rampa. Não me ocorre nada. Desço do palco pelas escadas de acesso para a plateia e subo a ligeira inclinação do corredor. Perto da porta, a porta que dá acesso ao foyer, olho para trás e relembro tudo o que vi naquele espaço e naquele tempo como uma memória presente. Saio e entregam-me um livro branco, só com fotografias, sobre os vários processos a que os tijolos foram sujeitos. No plasma do foyer, junto ao bengaleiro, passam frases de vários autores, de Henry David Thoreau a Jorge Luis Borges, sobre a temática do tempo.

O Projecto Teatral, composto por André Maranha, Gonçalo Ferreira de Almeida, Helena Tavares, João Rodrigues e Maria Duarte, é um dos mais interessantes colectivos que exploram os domínios e limites da semiótica teatral. Mantendo o mesmo discurso depurado e sintético 

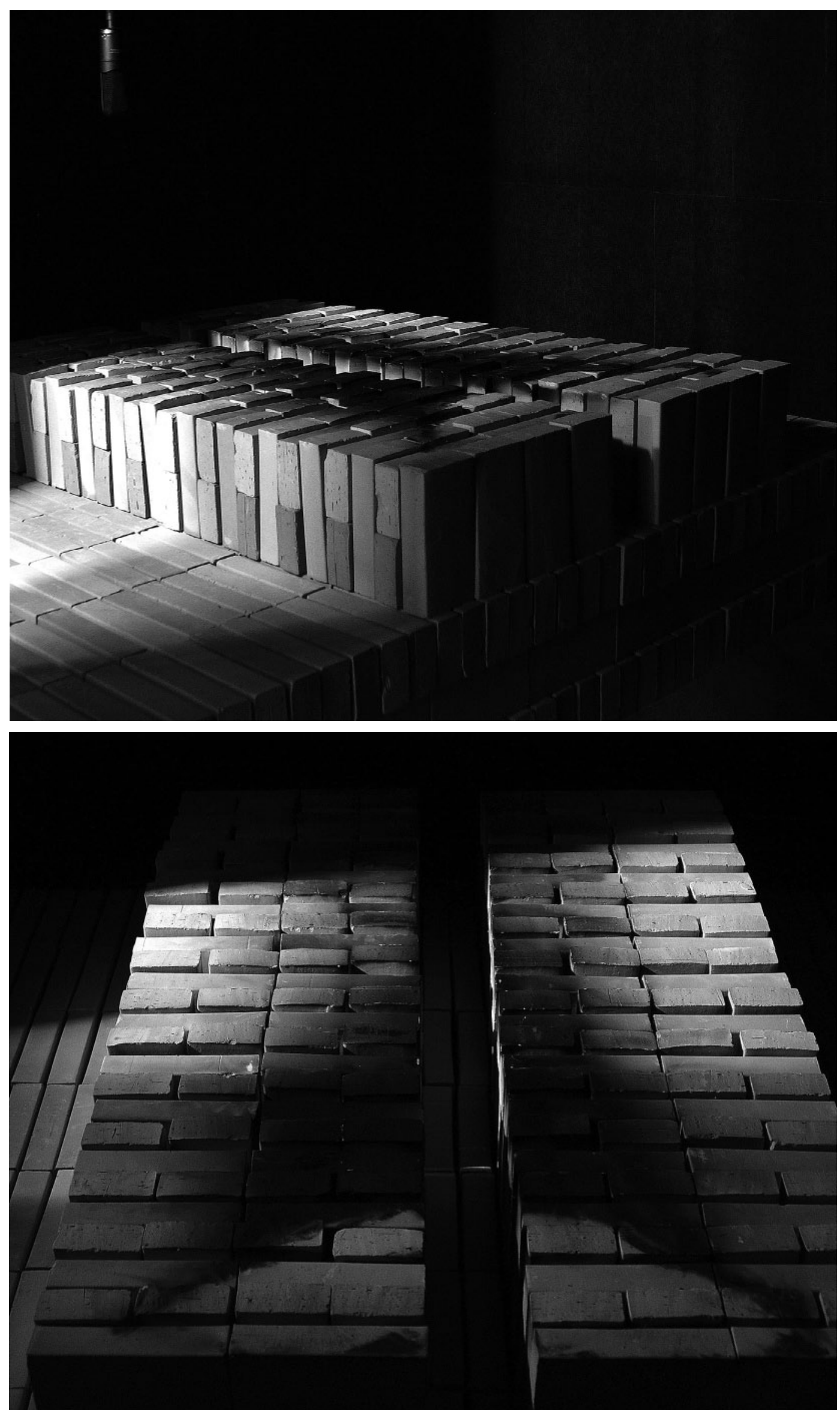

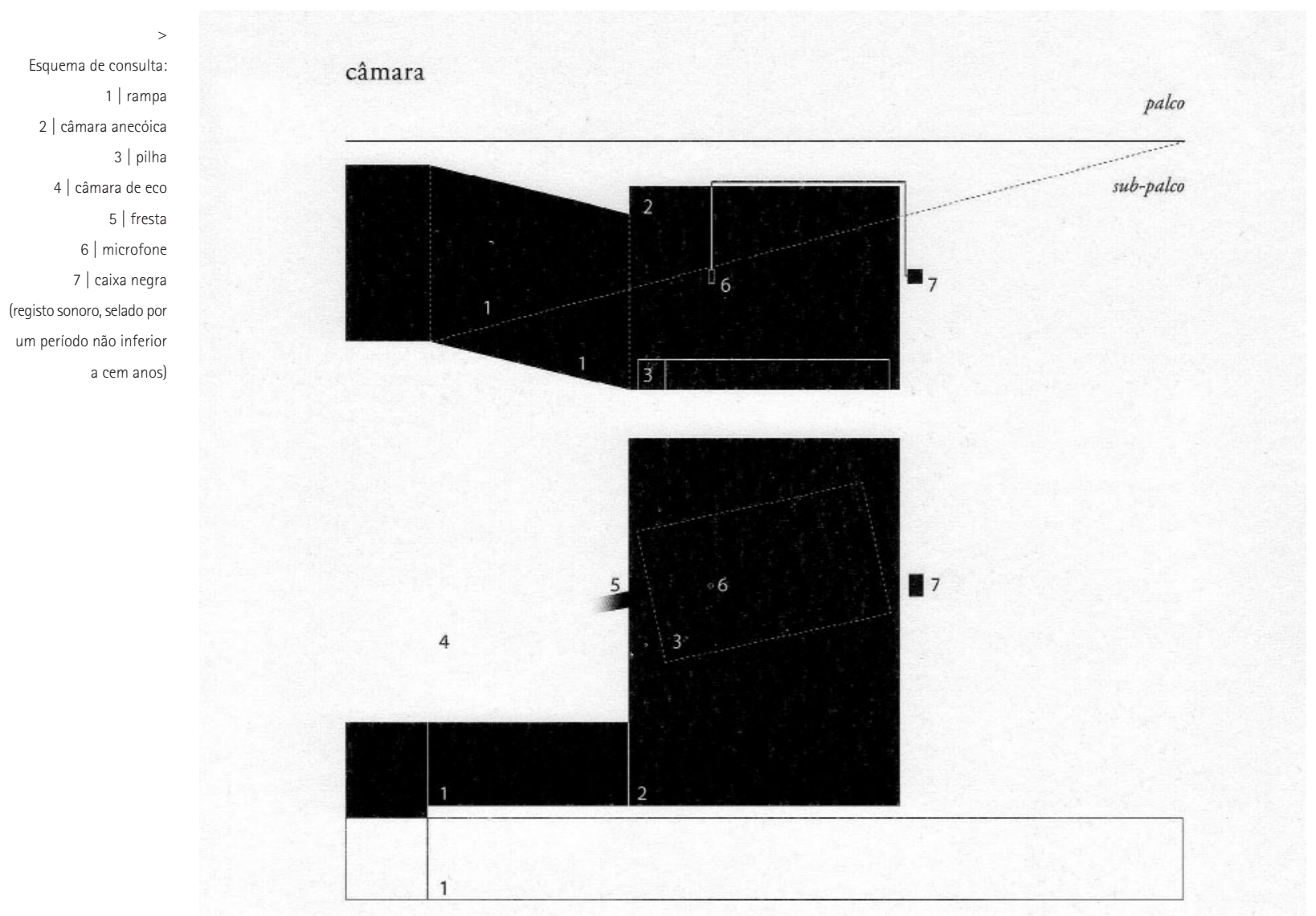

que a anterior produção, Vazio do teatro, apresentado em 2009 no espaço Negócio/ZDB, Câmara é um espectáculo que reflecte sobre a questão do tempo e, ao mesmo tempo, volta a (re)colocar o espectador numa posição de descoberta sobre o que é o teatro e a sua representação.

0 título sugere-nos dois elementos que nos podem ajudar a descortinar dramaturgicamente o tema. A câmara enquanto espaço, remete para o universo das pirâmides do Egipto e para os túmulos dos faraós. As câmaras são locais que romanticamente associamos ao silêncio, ao encerramento do tempo, ao tesouro e à morte. 0 próprio esquema é em muito semelhante às imagens de corte que descrevem o interior das pirâmides. Na História da arte de H.W. Janson pode ler-se: "A forma típica dos chamados 'túmulos particulares' era a mastaba, um montículo de forma quadrangular ou de pirâmide truncada, capeado de tijolo ou de pedra, erguido por cima da profunda câmara funerária subterrânea e ligado a esta por um poço" (Janson 1998: 56)

A palavra câmara está ainda associada à câmara escura. Um compartimento estanque à luz com um pequeno orifício de um dos lados. Ao colocar um objecto, do lado de fora, em frente ao orifício a sua imagem é projectada invertida. Esta câmara escura é o princípio base da fotografia. Fotografia que capta o momento presente e que o reifica quando revelado, tal como as imagens em repetição.

E onde é que está o teatro? Muitos acharão que estamos no domínio das artes plásticas contemporâneas, onde os objectos se interrogam a si próprios e testam os seus limites. Na verdade, o destaque dos objectos em cena, a sua disposição no espaço, o percurso que é necessário fazer para descobrir cada elemento, a experiência sensorial, pessoal e intransmissivel a que são submetidos os espectadores, a relação entre o sujeito e o objecto, já para não falar daquele mais óbvio argumento da ausência de actores e de texto, são tudo elementos que fazem parte deste espectáculo e que podem, sob o ponto de vista prático, apontar para aquele domínio. Mas, no fundo, não pertencerão todos estes signos também ao teatro enquanto disciplina artística? Objectos, como por exemplo o tijolo burro, preparado e fabricado, posicionado de uma determinada forma, não funcionará ele como um texto que nos questiona? E os actores, não serão os espectadores? Os que são deixados numa sala, com um esquema e um caminho que os guiam?

Na verdade, Câmara pensa sobre o teatro, tal como um objecto de arte se interroga a si mesmo. Nesse sentido, o Projecto Teatral não se afasta do palco para pensar sobre o teatro. Pelo contrário, assume-o e convida o espectador a experienciá-lo, a entrar nele e a descobrir o que existe debaixo dele, como se de uma prospecção arqueológica se tratasse. Descer até ao fundo, lá, onde está o escuro e a matéria com que se constrói o tempo e o teatro. Se isto é teatro? Sim, é, e o tempo acabará por construir essa ideia.

\section{Referência bibliográfica}

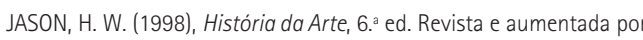
Anthony F. Jason, Trad. J. A. Ferreira de Almeida e Maria Manuela Rocheta Santos, colab. Jacinta Maria Matos, Lisboa, Fundção Caloustre Gulbenkian. 